\title{
Milk yield persistency in Brazilian Gyr cattle based on a random regression model
}

\author{
R.J. Pereira ${ }^{1}$, R.S. Verneque ${ }^{2}$, P.S. Lopes ${ }^{3}$, M.L. Santana Jr. ${ }^{4}$, \\ M.R. Lagrotta ${ }^{3}$, R.A. Torres ${ }^{3}$, A.E. Vercesi Filho ${ }^{5}$, M.A. Machado ${ }^{2}$ \\ 'Departamento de Zootecnia, Faculdade de Ciências Agrárias e Veterinárias, \\ Universidade Estadual Paulista "Júlio de Mesquita Filho", Jaboticabal, SP, Brasil \\ ${ }^{2}$ Embrapa Gado de Leite, Juiz de Fora, MG, Brasil \\ ${ }^{3}$ Departamento de Zootecnia, Universidade Federal de Viçosa, Viçosa, MG, Brasil \\ ${ }^{4}$ Instituto de Ciências Agrárias e Tecnológicas, \\ Universidade Federal de Mato Grosso, Rondonópolis, MT, Brasil \\ ${ }^{5}$ Agência Paulista de Tecnologia dos Agronegócios, Mococa, SP, Brasil
}

Corresponding author: R.J. Pereira

E-mail: rodjunper@yahoo.com.br

Genet. Mol. Res. 11 (2): 1599-1609 (2012)

Received June 6, 2011

Accepted December 15, 2011

Published June 15, 2012

DOI http://dx.doi.org/10.4238/2012.June.15.9

\begin{abstract}
With the objective of evaluating measures of milk yield persistency, 27,000 test-day milk yield records from 3362 first lactations of Brazilian Gyr cows that calved between 1990 and 2007 were analyzed with a random regression model. Random, additive genetic and permanent environmental effects were modeled using Legendre polynomials of order 4 and 5, respectively. Residual variance was modeled using five classes. The average lactation curve was modeled using a fourth-order Legendre polynomial. Heritability estimates for measures of persistency ranged from 0.10 to 0.25 . Genetic correlations between measures of persistency and 305-day milk yield (Y305) ranged from -0.52 to 0.03 . At high selection intensities for persistency measures and Y305, few animals were selected in common. As the selection intensity for the two traits decreased, a higher percentage of animals were selected in common. The average predicted breeding values for
\end{abstract}


Y305 according to year of birth of the cows had a substantial annual genetic gain. In contrast, no improvement in the average persistency breeding value was observed. We conclude that selection for total milk yield during lactation does not identify bulls or cows that are genetically superior in terms of milk yield persistency. A measure of persistency represented by the sum of deviations of estimated breeding value for days 31 to 280 in relation to estimated breeding value for day 30 should be preferred in genetic evaluations of this trait in the Gyr breed, since this measure showed a medium heritability and a genetic correlation with 305-day milk yield close to zero. In addition, this measure is more adequate at the time of peak lactation, which occurs between days 25 and 30 after calving in this breed.

Key words: Dairy cattle; Covariance function; Genetic parameters; Milk yield persistency

\section{INTRODUCTION}

The Gyr (Bos indicus) breed is present almost throughout Brazil, accounting for more than $80 \%$ of dairy herds as purebreds or as crossbreeds with Holstein cattle. This widespread distribution is mainly due to the fact that these animals can be raised on pasture, in addition to their resistance to endo- and ectoparasites and to high temperature.

One peculiar characteristic of pasture-based milk production systems is the nutritional limitation of peak milk yield of the animals. Peak milk yield is $14 \mathrm{~kg}$ milk/day for cows maintained exclusively on tropical grass systems and $30 \mathrm{~kg}$ milk/day for cows raised on intensively managed tropical pasture with concentrate supplements (Santos et al., 2007).

Milk yield persistency can be defined as the ability of a cow to maintain milk production after peak lactation. Therefore, one important trait that needs to be improved simultaneously with total milk yield in dairy cattle breeding programs addressing milk production on pasture is milk yield persistency, since this approach permits an increase in production by genetic modification of the shape of the lactation curve. As a consequence, more persistent cows produce higher amounts of milk during lactation without the need to increase peak yield, which is limited in these production systems. In addition, improvement of persistency may contribute to reducing the costs of production systems, since it is associated with reproductive efficiency, resistance to diseases, and feed and health care costs (Sölkner and Fuchs, 1987; Dekkers et al., 1998; Jakobsen et al., 2003).

Several measures of persistency have been proposed (Jamrozik et al., 1997; Jakobsen et al., 2002; Kistmaker, 2003). These measures are calculated using functions of estimated breeding values (EBV) for days in milk obtained with random regression models. Countries such as Canada and the Netherlands have already included the persistency trait in national genetic evaluations.

Milk yield persistency has not yet been studied in the Gyr breed and a better genetic understanding is therefore necessary to include this trait in genetic evaluations of this breed. The objective of the present study was to evaluate measures of milk yield persistency in first lactations of Gyr cows in order to identify the measure that can be applied to genetic evaluations of animals using random regression models. 


\section{MATERIAL AND METHODS}

A total of 62,758 test-day milk yield (TDMY) records from 7552 first lactations of Brazilian Gyr cows that calved between 1990 and 2007 were used. The age of the cows at calving ranged from 24 to 60 months. The data were obtained from the National Animal Science Archive, managed by the Brazilian National Center for Dairy Cattle Research (Embrapa Gado de Leite). Test-day records obtained between 5 and 305 days of lactation were used. The following criteria were used for inclusion of the cows in the study: first test-day record obtained within 45 days after calving; interval of 15 to 45 days between test days; and more than 3 test-day records. In addition, the availability of a contemporary group, characterized by herd-year-test month (HYM) with at least three cows (daughters of at least two bulls), was established. After data consistency, 27,000 TDMY records from 3362 cows (daughters of 507 bulls), which belonged to 56 herds, were used in the analyses. Most herds were located in the southeast region of Brazil and the remaining ones were from the northeast, midwest, and south regions. After identification of the relationship between animals for five generations, the pedigree file contained 8590 animals.

The TDMY data were modeled using a random regression model considering a fourth-order Legendre polynomial (LP) for the additive genetic effect and fifth-order for the permanent environmental effect. The average lactation curve was modeled using a fourth-order LP.

Heterogeneity of residual variance was considered, which was constant within but heterogenous between classes of days in milk. The residual variance classes were formed by grouping the days of lactation as follows: 5-30, 31-60, 61-120, 121-270, and 271-305 days in milk.

The random regression model used in the analyses is represented as:

$$
\mathrm{y}_{\mathrm{ijk}}=\mathrm{HYM}_{\mathrm{i}}+\sum_{\mathrm{n}=1}^{2} \mathrm{~b}_{\mathrm{n}} \mathrm{x}_{\mathrm{j}}^{\mathrm{n}}+\sum_{\mathrm{m}=0}^{3} \beta_{\mathrm{m}} \varphi_{\mathrm{m}}(\mathrm{t})+\sum_{\mathrm{m}=0}^{3} \alpha_{\mathrm{jm}} \varphi_{\mathrm{m}}(\mathrm{t})+\sum_{\mathrm{m}=0}^{4} \mathrm{p}_{\mathrm{jm}} \varphi_{\mathrm{m}}(\mathrm{t})+\mathrm{e}_{\mathrm{ijk}},
$$

where $y_{\mathrm{ijk}}$ is the $k^{\text {th }}$ observation recorded on lactation day $t$ of animal $j$ in $\mathrm{HYM}_{\mathrm{i}}$; $\mathrm{HYM}_{\mathrm{i}}$ is the effect of the $i^{\text {th }}$ contemporary group (2325 classes); $b_{\mathrm{n}}$ is the regression coefficient for linear $(n=1)$ and quadratic $(n=2)$ effects of TDMY as a function of age $x_{\mathrm{j}}$ of the cow at calving, in months; $\beta_{\mathrm{m}}$ is the set of $m$ fixed regression coefficients to model the average trajectory of the population; $\varphi_{\mathrm{m}}(\mathrm{t})$ is a covariate of the LP according to lactation day $(\mathrm{t}) ; \alpha_{j m}, p_{j m}$ are sets of $m$ additive genetic and permanent environmental random regression coefficients for each cow $j$, and $e_{\mathrm{ijk}}$ is the random error or temporary measurement error associated with observation $k$ of cow $j$ belonging to $\mathrm{HYM}_{\mathrm{i}}$.

The random regression model can be rewritten in matrix form as:

$$
\mathrm{y}=\mathrm{X} \beta+\mathrm{Za}+\mathrm{Wp}+\mathrm{e},
$$

where $y$ is the vector of observations, $\beta$ is the vector of fixed effects, $a$ is the vector of random regression coefficients of the additive genetic effect of the animal, $p$ is the vector of random regression coefficients of the permanent environmental effect, $e$ is the vector of the residual random effect, and $X, Z$ and $W$ are incidence matrices corresponding to observations for fixed effects, random effects of the animal and permanent environmental effects, respectively. It was assumed that: 


$$
\left[\begin{array}{c}
\mathbf{a} \\
\mathbf{p} \\
\mathbf{e}
\end{array}\right] \sim \mathbf{N}(\mathbf{0}, \mathbf{V}), \mathbf{V}=\left[\begin{array}{ccc}
\boldsymbol{\Lambda}_{\mathrm{A}} \otimes \mathbf{A} & \mathbf{0} & \mathbf{0} \\
\mathbf{0} & \boldsymbol{\Lambda}_{\mathrm{P}} \otimes \mathbf{I} & \mathbf{0} \\
\mathbf{0} & \mathbf{0} & \mathbf{R}
\end{array}\right]
$$

where: $\Lambda_{A}$ and $\Lambda_{P}$ are matrices of additive genetic covariance and permanent environmental effect for the random regression coefficients, respectively; $A$ is the numerator relationship matrix between animals; $I$ is an identity matrix; $\otimes$ is the direct product between matrices, and $R=\operatorname{diag}\left\{\sigma^{2}{ }_{\mathrm{es}}\right\}$, where $s$ corresponds to the class of days in milk to fit heterogenous residual variances. Thus, $s=1,2,3,4$, or 5 .

The solutions for the additive genetic random regression coefficients of animal $j$ are represented as $\hat{a}_{j}^{\prime}=\left[\hat{a}_{0} \hat{a}_{1} \hat{a}_{2} \hat{a}_{3}\right]$. The EBV of animal $j$ on day $t$ of lactation was obtained by:

$$
\mathrm{EBV}_{\mathrm{jt}}=\mathrm{C}_{\mathrm{t}} \hat{\mathrm{a}}_{\mathrm{j}} \text {, }
$$

where $C_{\mathrm{t}}$ is the vector of covariates of the LP on day $t$ of lactation. tained by:

The estimated breeding value for 305 -day milk yield $\left(\mathrm{EBV}_{305}\right)$ of animal $j$ was ob-

$$
\mathrm{EBV}_{305}=\sum_{\mathrm{t}=5}^{305} \mathrm{EBV}_{\mathrm{jt}}
$$

Six measures of milk yield persistency $\left(\mathrm{PS}_{\mathrm{i}}\right)$ based on the EBV for different periods of lactation were evaluated (Table 1). Higher values for $\mathrm{PS}_{\mathrm{i}}$ indicate more persistent lactation.

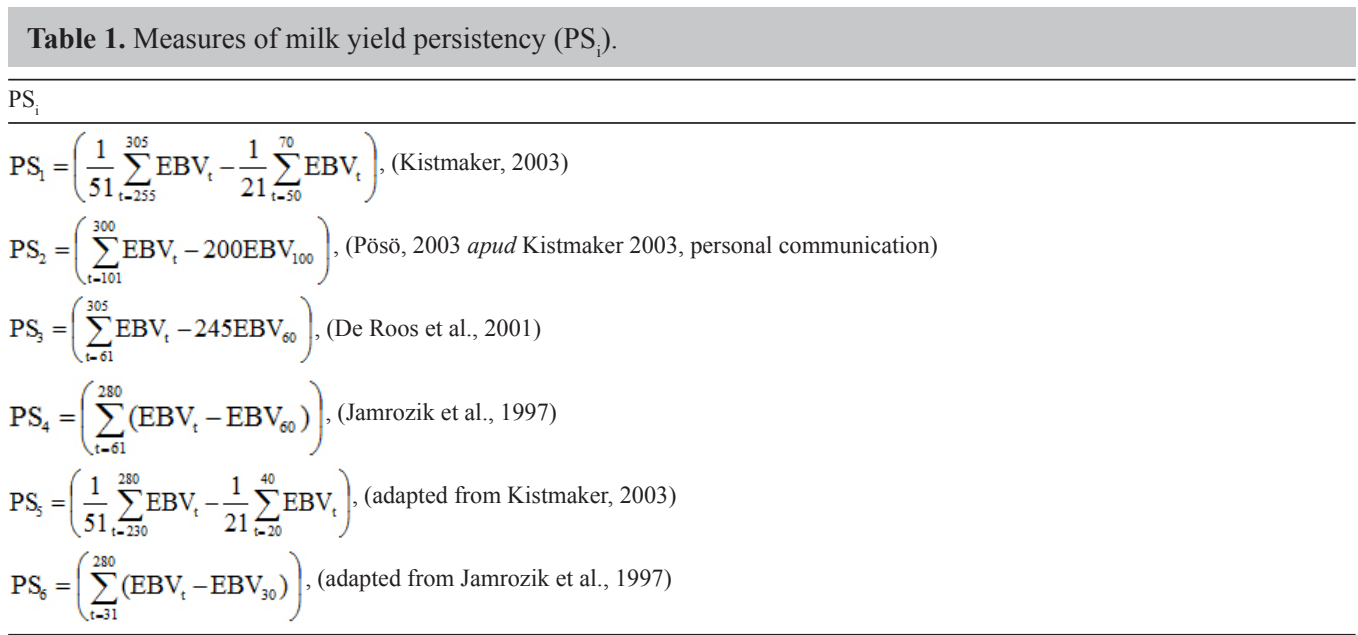

The covariance components were estimated by the restricted maximum likelihood method using the WOMBAT program (Meyer, 2007).

The genetic variances for $\mathrm{PS}_{\mathrm{i}}\left(\hat{\sigma}_{\mathrm{aPSi}}^{2}\right)$ were obtained by:

$$
\hat{\sigma}_{\mathrm{aPSi}}^{2}=\mathbf{f}_{\mathrm{i}}^{\prime} \mathbf{\Lambda}_{\mathrm{A}} \mathbf{f}_{\mathrm{i}},
$$


where $f_{i}^{\prime}$ is the vector of covariates corresponding to the function of the measure of persistency, and $\Lambda_{A}$ is the matrix of additive genetic covariances between random regression coefficients. Permanent environmental variances for $\mathrm{PS}_{\mathrm{i}}\left(\hat{\sigma}_{\text {pePsi }}^{2}\right)$ were obtained in a similar manner by replacing $\Lambda_{\mathrm{A}}$ with $\Lambda_{\mathrm{p}}$, the matrix of permanent environmental covariances between random regression coefficients.

The heritabilities of the persistency measures $\left(\mathrm{h}_{\mathrm{PSi}}^{2}\right)$ were calculated using the equation:

$$
\mathrm{h}_{\mathrm{PSi}}^{2}=\hat{\sigma}_{\mathrm{aPSi}}^{2} /\left(\hat{\sigma}_{\mathrm{aPSi}}^{2}+\hat{\sigma}_{\mathrm{pePSi}}^{2}+\hat{\sigma}_{\mathrm{ePSi}}^{2}\right) .
$$

The residual variances for $\mathrm{PS}_{\mathrm{i}}\left(\hat{\sigma}_{\mathrm{ePSi}}^{2}\right)$ were obtained as follows:

$$
\begin{gathered}
\hat{\sigma}_{\mathrm{ePS}}^{2}=\mathrm{V}_{\mathrm{e}}\left(\mathrm{PS}_{\mathrm{t}}\right)=\mathrm{V}_{\mathrm{e}}\left[\left(\frac{1}{51} \sum_{\mathrm{t}=255}^{305} \mathrm{MY}_{\mathrm{t}}\right)-\left(\frac{1}{21} \sum_{\mathrm{t}=50}^{70} \mathrm{MY}_{\mathrm{t}}\right)\right] ; \\
\mathrm{V}_{\mathrm{e}}\left(\mathrm{PS}_{1}\right)=\mathrm{V}_{\mathrm{e}}\left(\frac{1}{51} \sum_{\mathrm{t}=255}^{305} \mathrm{MY}_{\mathrm{t}}\right)+\left(\frac{1}{21} \sum_{\mathrm{t}=50}^{70} \mathrm{MY}_{\mathrm{t}}\right)-2 \mathrm{COV}_{\mathrm{e}}\left[\left(\frac{1}{51} \sum_{\mathrm{t}=255}^{305} \mathrm{MY} \mathrm{t}\right),\left(\frac{1}{21} \sum_{\mathrm{t}=50}^{70} \mathrm{MY} \mathrm{Y}_{\mathrm{t}}\right)\right] \\
\mathrm{V}_{\mathrm{e}}\left(\mathrm{PS}_{1}\right)=\frac{\left[\mathrm{V}_{\mathrm{e}}\left(\mathrm{MY}_{255}\right)+\ldots+\mathrm{V}_{\mathrm{e}}\left(\mathrm{MY}_{305}\right)+2550 \mathrm{COV}_{\mathrm{e}}\left(\mathrm{MY}_{\mathrm{t}}, \mathrm{MY}_{\mathrm{t}}\right)\right]}{51^{2}}+ \\
+\frac{\left[\mathrm{V}_{\mathrm{e}}\left(\mathrm{MY}_{50}\right)+\ldots+\mathrm{V}_{\mathrm{e}}\left(\mathrm{MY}_{70}\right)+420 \mathrm{COV}_{\mathrm{e}}\left(\mathrm{MY}_{\mathrm{t}}, \mathrm{MY}_{\mathrm{t}}\right)\right]}{21^{2}}-2 \mathrm{COV}_{\mathrm{e}}\left[\left(\frac{1}{51} \sum_{\mathrm{t}=255}^{305} \mathrm{MY}_{\mathrm{t}}\right),\left(\frac{1}{21} \sum_{\mathrm{t}=50}^{70} \mathrm{MY}_{\mathrm{t}}\right)\right],
\end{gathered}
$$

where $t$ is the day of lactation and $M Y_{t}$ is the milk yield on day $t$.

Since in the present study the residual variances were considered to be independent and $t$ is always different from $t^{\prime}$, the terms containing $\mathrm{COV}_{\mathrm{e}}$ are equal to zero. Thus,

$$
\mathrm{V}_{\mathrm{e}}\left(\mathrm{PS}_{1}\right)=\left[\mathrm{V}_{\mathrm{e}}\left(\mathrm{MY}_{255}\right)+\ldots+\mathrm{V}_{\mathrm{e}}\left(\mathrm{MY}_{305}\right)\right] / 51^{2}+\left[\mathrm{V}_{\mathrm{e}}\left(\mathrm{MY}_{50}\right)+\ldots+\mathrm{V}_{\mathrm{e}}\left(\mathrm{MY}_{70}\right)\right] / 21^{2}
$$

According to the residual variance classes used, $\mathrm{V}_{\mathrm{e}}\left(\mathrm{MY}_{5}\right)$ to $\mathrm{V}_{\mathrm{e}}\left(\mathrm{MY}_{30}\right)=\hat{\sigma}_{e 1} ; \mathrm{V}_{\mathrm{e}}\left(\mathrm{MY}_{31}\right)$ to $\mathrm{V}_{\mathrm{e}}\left(\mathrm{MY}_{60}\right)=\hat{\sigma}_{e 2} ; \mathrm{V}_{\mathrm{e}}\left(\mathrm{MY}_{61}\right)$ to $\mathrm{V}_{\mathrm{e}}\left(\mathrm{MY}_{120}\right)=\hat{\sigma}_{e 3}, \mathrm{~V}_{\mathrm{e}}\left(\mathrm{MY}_{121}\right)$ to $\mathrm{V}_{\mathrm{e}}\left(\mathrm{MY}_{270}\right)=\hat{\sigma}_{e 4}$, and $\mathrm{V}_{\mathrm{e}}\left(\mathrm{MY}_{271}\right)$ to $\mathrm{V}_{\mathrm{e}}\left(\mathrm{MY}_{305}\right)=\hat{\sigma}_{e 5}$. Therefore, $\hat{\sigma}_{\mathrm{ePS}}^{2}=\mathrm{V}_{\mathrm{e}}\left(\mathrm{PS}_{1}\right)=\left[\left(16 \hat{\sigma}_{\mathrm{e} 4}^{2}+35 \hat{\sigma}_{\mathrm{e} 5}^{2}\right) / 51^{2}\right]+\left[\left(11 \hat{\sigma}_{\mathrm{e} 2}^{2}+10 \hat{\sigma}_{\mathrm{e} 3}^{2}\right) / 21^{2}\right] . \hat{\sigma}_{\mathrm{ePSi}}^{2}$ values were obtained in a similar manner for the other measures of $\mathrm{PS}_{i}$.

\section{RESULTS AND DISCUSSION}

TDMY was $9.2 \mathrm{~kg}$, with a standard deviation of $3.6 \mathrm{~kg}$ and a coefficient of variation of $38.9 \%$. An increase in milk production (Table 2) was observed during the first three fortnightly intervals. After the third fortnightly interval, production decreased gradually until the end of lactation.

The average lactation curves obtained for cows with milk production and for bulls that had at least one female offspring with milk production are shown in Figure 1. Both curves showed a similar course and peak breeding values occurred between days 25 and 30 of lactation.

Table 3 shows the heritability estimates for the six PS and for 305-day milk yield (Y305), as well as the genetic correlations between $\mathrm{PS}_{\mathrm{i}}$ and between these measures and Y305. The heritabilities estimated for $\mathrm{PS}_{1}, \mathrm{PS}_{5}$ and $\mathrm{PS}_{6}$ were medium, a finding indicating a substantial genetic component for this trait in the Gyr breed. On the other hand, the heritability estimates for $\mathrm{PS}_{2}, \mathrm{PS}_{3}$, and $\mathrm{PS}_{4}$ were lower. The differences between heritabilities for $\mathrm{PS}_{\mathrm{i}}$ measures might be attributed 
to the stage of lactation and to the method used for their estimation (Madsen, 1975). Using data from Danish Holstein animals, Jakobsen et al. (2002) estimated a heritability of 0.09 for $\mathrm{PS}_{4}$, a value close to that obtained in the present study (0.10). Cobuci et al. (2006) analyzed data from Brazilian Holstein animals using fourth-order LP and assuming homogenous residual variance during lactation. The authors obtained heritability estimates of $0.09,0.15$ and 0.19 for $\mathrm{PS}_{1}, \mathrm{PS}_{2}$ and $\mathrm{PS}_{3}$, respectively.

\section{Table 2. Milk yield according to days in milk.}

\begin{tabular}{|c|c|c|c|c|}
\hline Days in milk & $\mathrm{N}$ & Mean $(\mathrm{kg})$ & $\mathrm{SD}(\mathrm{kg})$ & CV $(\%)$ \\
\hline $5-19$ & 1338 & 10.0 & 3.7 & 37.2 \\
\hline $20-34$ & 1616 & 10.7 & 3.7 & 35.0 \\
\hline $35-49$ & 1596 & 10.9 & 3.9 & 36.1 \\
\hline $50-64$ & 1570 & 10.4 & 3.6 & 34.8 \\
\hline $65-79$ & 1601 & 10.3 & 3.7 & 36.3 \\
\hline $80-94$ & 1539 & 10.0 & 3.5 & 35.4 \\
\hline 95-109 & 1581 & 9.7 & 3.6 & 37.0 \\
\hline $110-124$ & 1469 & 9.6 & 3.4 & 36.1 \\
\hline $125-139$ & 1481 & 9.4 & 3.5 & 36.9 \\
\hline $140-154$ & 1381 & 9.2 & 3.4 & 36.9 \\
\hline $155-169$ & 1416 & 9.0 & 3.3 & 36.7 \\
\hline $170-184$ & 1345 & 8.7 & 3.2 & 36.8 \\
\hline $185-199$ & 1348 & 8.6 & 3.2 & 37.5 \\
\hline $200-214$ & 1272 & 8.3 & 3.1 & 37.2 \\
\hline $215-229$ & 1284 & 8.1 & 3.1 & 38.2 \\
\hline $230-244$ & 1160 & 7.8 & 3.1 & 39.4 \\
\hline $245-259$ & 1160 & 7.8 & 3.1 & 40.0 \\
\hline $260-274$ & 1032 & 7.5 & 3.0 & 39.6 \\
\hline $275-289$ & 973 & 7.4 & 3.0 & 40.8 \\
\hline $290-305$ & 838 & 7.3 & 2.9 & 39.8 \\
\hline
\end{tabular}

$\mathrm{N}=$ number of observations; $\mathrm{SD}=$ standard deviation; $\mathrm{CV}=$ coefficient of variation.

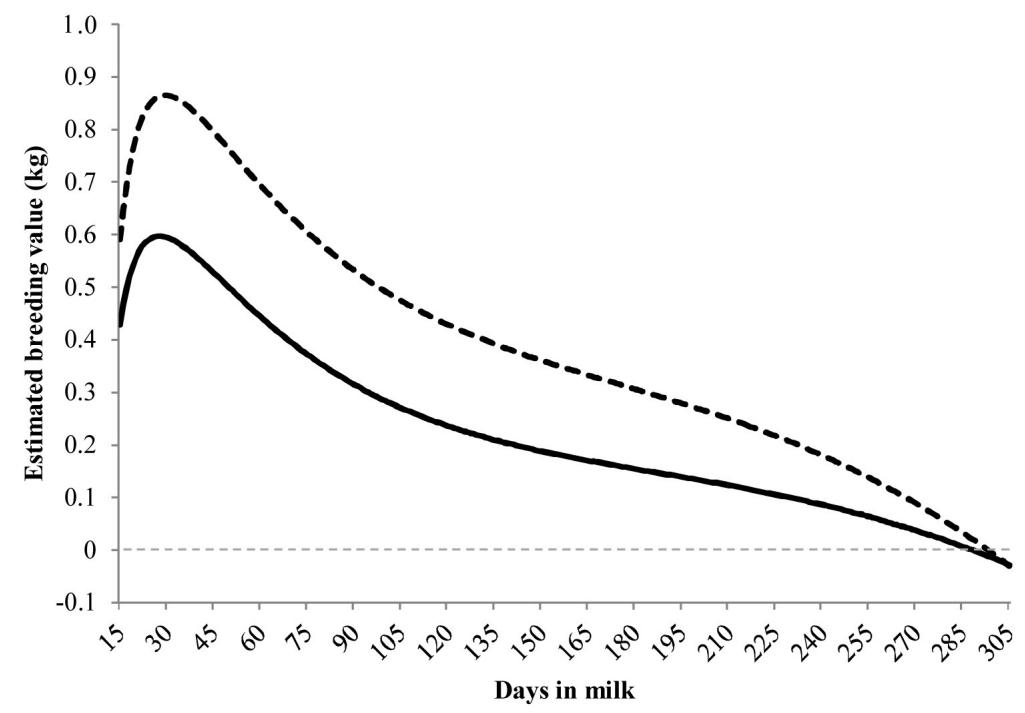

Figure 1. Average lactation curves obtained for cows with milk production (dashed line) and for bulls with at least one female offspring with known milk production (full line). 
Table 3. Heritability estimates (diagonal, in bold) and genetic correlations (above the diagonal) between persistency measures $\left(\mathrm{PS}_{\mathrm{i}}\right)$ and between these measures and 305-day milk yield (Y305).

\begin{tabular}{llcccccc}
\hline Trait & $\mathrm{Y305}$ & $\mathrm{PS}_{1}$ & $\mathrm{PS}_{2}$ & $\mathrm{PS}_{3}$ & $\mathrm{PS}_{4}$ & $\mathrm{PS}_{5}$ & $\mathrm{PS}_{6}$ \\
\hline Y305 & $\mathbf{0 . 2 2}$ & -0.46 & -0.52 & -0.32 & -0.28 & -0.25 & 0.03 \\
PS $_{1}$ & & $\mathbf{0 . 2 5}$ & 0.95 & 0.95 & 0.92 & 0.90 & 0.59 \\
PS $_{2}$ & & $\mathbf{0 . 1 4}$ & 0.86 & 0.82 & 0.76 & 0.38 \\
PS $_{3}$ & & & $\mathbf{0 . 1 2}$ & 0.99 & 0.98 & 0.80 \\
PS $_{4}$ & & & & & 0.99 & 0.83 \\
PS $_{5}$ & & & & & $\mathbf{0 . 2 4}$ & 0.88 \\
PS $_{6}$ & & & & & & $\mathbf{0 . 1 6}$ \\
\hline
\end{tabular}

The genetic correlations between $\mathrm{PS}_{\mathrm{i}}$ were generally high, indicating a strong association between these measures. However, $\mathrm{PS}_{6}$ showed lower genetic correlations with $\mathrm{PS}_{1}$ and $\mathrm{PS}_{2}$, indicating that these different measures resulted in re-ranking of animals. The genetic correlations between $\mathrm{PS}_{\mathrm{i}}$ and Y305 were negative for $\mathrm{PS}_{1}, \mathrm{PS}_{2}, \mathrm{PS}_{3}, \mathrm{PS}_{4}$, and $\mathrm{PS}_{5}$. On the other hand, the genetic correlation between $\mathrm{PS}_{6}$ and Y305 was close to zero. In studies on Holstein cattle using random regression models, the genetic correlations between different persistency measures and 305-day milk yield ranged from -0.49 to 0.57 (Jakobsen et al., 2002; Kistemaker, 2003; Cobuci et al., 2004, 2006).

$\mathrm{PS}_{6}$ showed medium heritability and genetic correlations with Y305 close to zero (0.03), desired characteristics of a persistency measure (Dekkers et al., 1998). A persistency measure should show a low correlation with cumulative milk yield during lactation, since otherwise, its inclusion in genetic breeding programs would not be necessary or, if this genetic correlation is negative, the selection for persistency will negatively affect the genetic gain for milk yield.

The percentage of cows or bulls selected in common when different proportions of individuals were selected for persistency $\left(\mathrm{PS}_{6}\right)$ and $\mathrm{Y} 305$ is shown in Table 4. As expected, a higher percentage of animals were selected in common as the intensity of selection for the two traits decreased.

Table 4. Percentage of cows or bulls selected in common when different proportions of individuals (b) are selected for persistency ( $\mathrm{PS}_{6}$ ) and 305-day milk yield.

\begin{tabular}{lrrrrrr}
\hline & \multicolumn{7}{c}{$\mathrm{b}(\%)$} \\
\cline { 2 - 7 } & 1 & 5 & 10 & 20 & 40 & 60 \\
\hline Cows in common (\%) & 3 & 6 & 8 & 14 & 27 & 50 \\
Bulls* in common (\%) & 0 & 0 & 10 & 19 & 22 & 49 \\
\hline
\end{tabular}

*Bulls with 8 or more female offspring with known milk production.

Comparison of the five best bulls with at least eight daughters, classified based on $\mathrm{EBV}_{305}$ (Figure 2), showed different genetic patterns during lactation for animals with similar breeding values. Bulls B2, B3 and B4 were expected to show higher breeding values for milk yield persistency than bulls B1 and B5.

Similarly, Figure 3 illustrates the genetic curves obtained for the five best bulls with at least 8 daughters classified based on $\mathrm{PS}_{6}$. In general, the best bulls for milk yield persistency showed negative, although increasing, breeding values almost throughout lactation, except for bull B2. Taken together, these results show that persistency does not depend on the level 
of milk production or breeding value for milk yield and is related to the shape of the lactation curve. This supports the auxiliary character of persistency and indicates the need of simultaneous selection for milk yield, since exclusive selection for persistency does not permit genetic improvement of milk production and vice versa. Figure 4 shows two bulls with the same $\mathrm{EBV}_{305}(483.5 \mathrm{~kg})$ and opposite breeding values for PS 6 . Bull A would be more desired than bull B, since it had a superior genetic lactation pattern, transmitting higher milk yield persistency to its progeny. It is expected that bull A transmitted to its female offspring a small increase in peak yield and a marked increase in production after peak lactation. The opposite should have been observed for daughters of bull B.

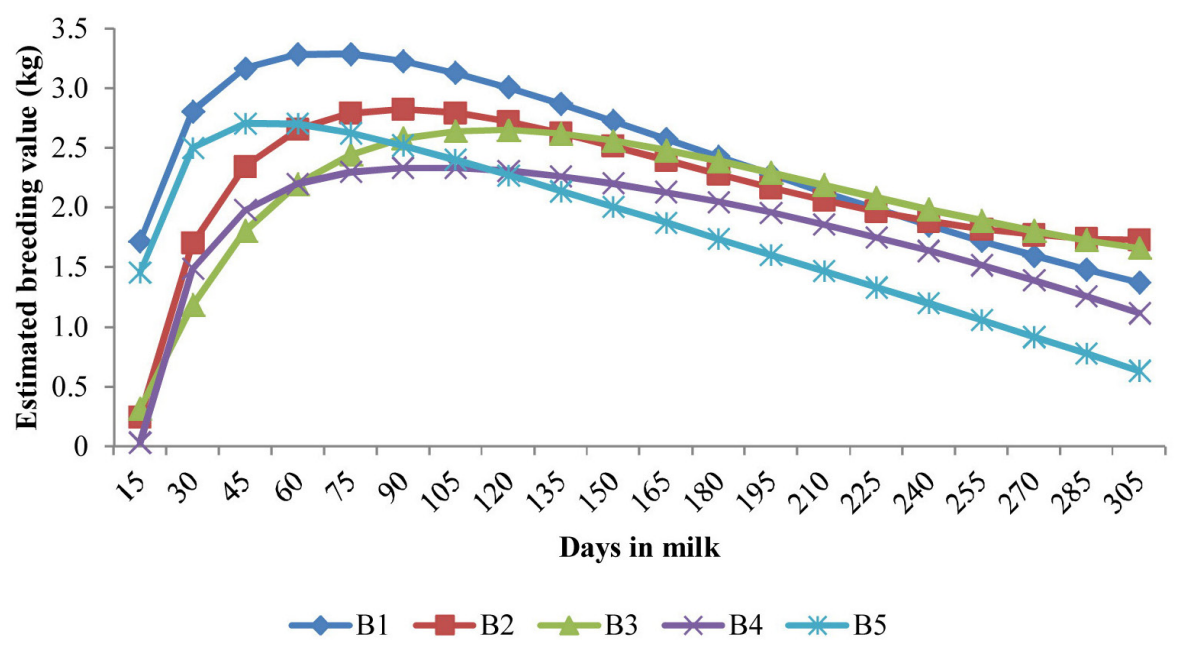

Figure 2. Estimated breeding values along lactation obtained for the five best bulls (B1-B5) classified based on 305-day milk yield with 8 or more daughters.

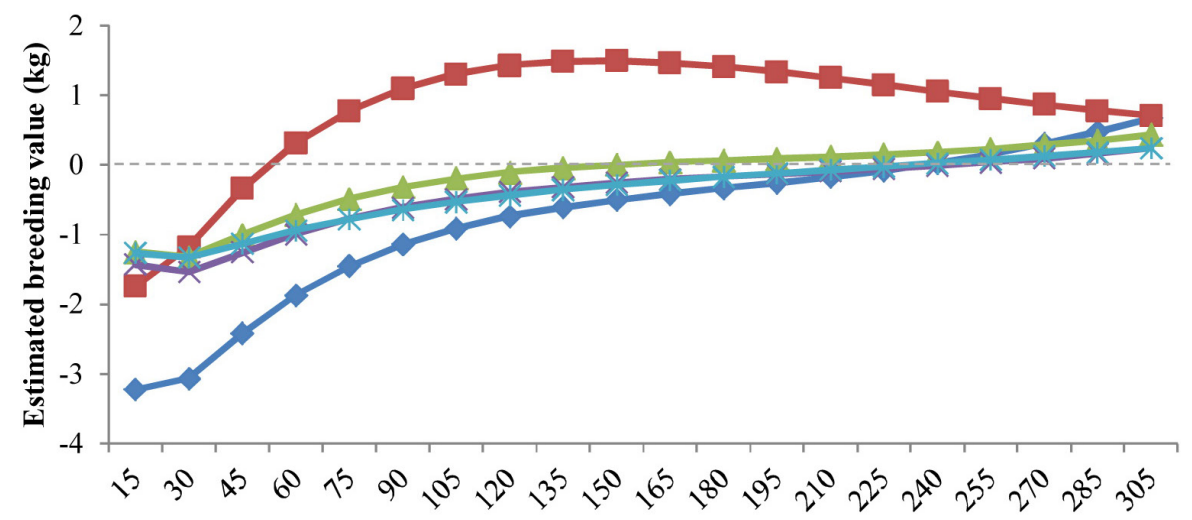

Days in milk

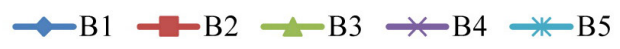

Figure 3. Estimated breeding values along lactation obtained for the five best bulls (B1-B5) classified based on $\mathrm{PS}_{6}$ with 8 or more daughters. 


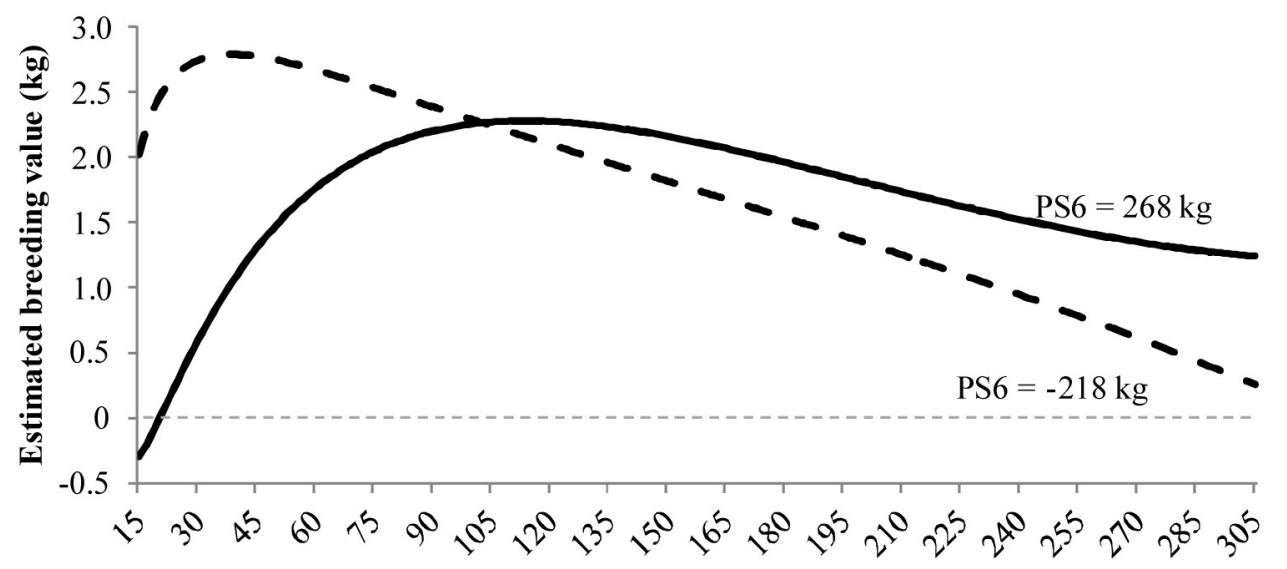

Days in milk

Bull A - Bull B

Figure 4. Estimated breeding values along lactation obtained for two bulls (A and B) with the same predicted breeding value for 305 -day milk yield $(483.5 \mathrm{~kg}$ ) and opposite breeding values for PS.

The mean $\mathrm{EBV}_{305}$ values according to year of birth of the cows (Figure 5) demonstrate a substantial annual genetic gain in Y305, confirming the effectiveness of the national breeding program of this breed. In contrast, there was no genetic gain in persistency ( $\mathrm{PS}_{6}$ ) (Figure 5).

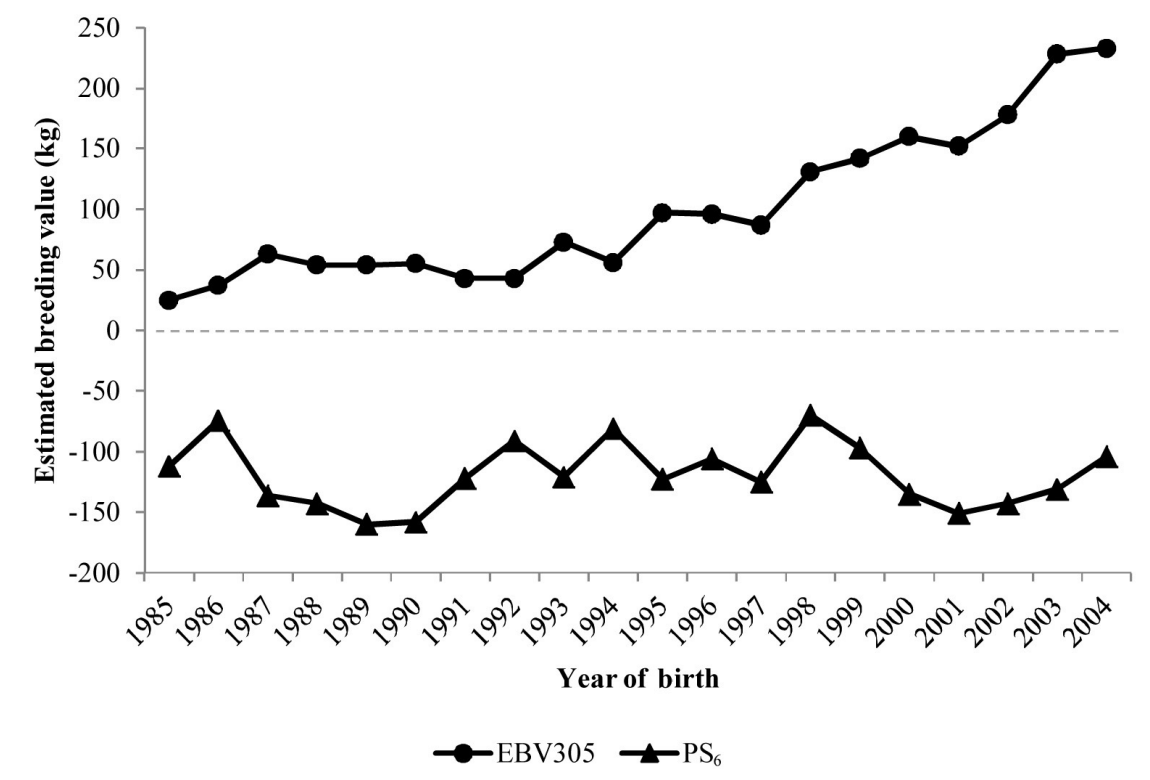

Figure 5. Mean estimated breeding values for 305-day milk yield (EBV305) and milk yield persistency (PS $)$ according to year of birth of the cows. 
The present results indicate that selection for Y305 did not result in significant improvement of milk yield persistency, a functional trait that is related to a reduction in feed, health care and reproduction costs (Sölkner and Fuchs, 1987; Dekkers et al., 1998; Jakobsen et al., 2003). Strategies of simultaneous selection for milk yield and persistency using selection indices have been investigated by Togashi and Lin $(2006,2007)$.

Pereira et al. (2011) showed that, for milk yield persistency of Gyr cattle, the lack of adjusting for the effect of pregnancy overestimates breeding values of nonpregnant cows or cows with long days open and underestimates breeding values of cows with short days open. Therefore, this effect should be considered on genetic evaluations for this trait.

The effect of the use of somatotropin, which is generally not included in genetic evaluation models of dairy cattle in Brazil, should be investigated in the Gyr breed to determine its possible influence on genetic evaluations of milk yield and persistency.

\section{CONCLUSIONS}

Among the measures of milk yield persistency studied, $\mathrm{PS}_{6}$ should be preferred in genetic evaluations of this trait in the Gyr breed, since this measure showed a medium heritability and a genetic correlation with 305-day milk yield close to zero. In addition, this measure is more adequate at the time of peak lactation, which occurs between days 25 and 30 after calving in this breed. Simultaneous selection for persistency and milk yield is recommended to obtain genetic gains in milk yield and to change the shape of the lactation curve in a desirable direction.

\section{ACKNOWLEDGMENTS}

Research supported by the Brazilian funding agency Coordenação de Aperfeiçoamento de Pessoal de Nível Superior (CAPES).

\section{REFERENCES}

Cobuci JA, Euclydes RF, Costa CN, Lopes PS, et al. (2004). Análises da persistência na lactação de vacas da raça holandesa, usando produção no dia do controle e modelo de regressão aleatória. Rev. Bras. Zootec. 33: 546-554.

Cobuci JA, Costa CN, Teixeira NM and Freitas AF (2006). Utilização dos polinômios de Legendre e da função de Wilmink em avaliações genéticas para persistência na lactação de animais da raça Holandesa. Arq. Bras. Med. Vet. Zootec. 58: 614-623.

De Roos APW, Harbers AGF and de Jong G (2001). Random regression test-day model in The Netherlands. Interbull Bull. 27: 155-158.

Dekkers JCM, Ten Hag JH and Weersink A (1998). Economic aspects of persistency of lactation in dairy cattle. Livest. Prod. Sci. 53: 237-252.

Jakobsen JH, Madsen P, Jensen J, Pedersen J, et al. (2002). Genetic parameters for milk production and persistency for Danish Holstein estimated in random regression models using REML. J. Dairy Sci. 85: 1607-1616.

Jakobsen JH, Rekaya R, Jensen J, Sorensen DA, et al. (2003). Bayesian estimates of covariance components between lactation curve parameters and disease liability in Danish Holstein cows. J. Dairy Sci. 86: 3000-3007.

Jamrozik J, Schaeffer LR and Dekkers JCM (1997). Genetic evaluation of dairy cattle using test day yields and random regression model. J. Dairy Sci. 80: 1217-1226.

Kistemaker GJ (2003). Comparison of persistency definitions in random regression test day models. Interbull Bull. 30: 96-98.

Madsen O (1975). A comparison of some suggested measures of persistency of milk yield in dairy cows. Anim. Prod. 20: $191-197$.

Meyer K (2007). WOMBAT: a tool for mixed model analyses in quantitative genetics by restricted maximum likelihood (REML). J. Zhejiang Univ. Sci. 8: 815-821. 
Pereira RJ, Santana ML Jr, Bignardi AB, Verneque RS, et al. (2011). Effect of pregnancy on the genetic evaluation of dairy cattle. Genet. Mol. Res. 10: 2190-2201.

Santos FAP, Martinez JC, Greco LF, Carareto R, et al (2007). Suplementação de Vacas sob Pastejo: Considerações Técnicas e Econômicas Visando Maior Rentabilidade. Proceedings of the 8th Simpósio Internacional de Produção Intensiva de Leite. INTERLEITE, Uberlândia, 249-300.

Sölkner J and Fuchs W (1987). A comparison of different measures of persistency with special respect to variation of Testday milk yields. Livest. Prod. Sci. 16: 305-319.

Togashi K and Lin CY (2006). Selection for milk production and persistency using eigenvectors of the random regression coefficient matrix. J. Dairy Sci. 89: 4866-4873.

Togashi K and Lin CY (2007). Improvement of lactation milk and persistency using the eigenvectors of the genetic covariance matrix between lactation stages. Livest. Sci. 110: 64-72. 